\title{
La planificación del borde costero chileno. Una normativa deficiente ${ }^{1}$
}

\section{The planning of the Chilean coastal border. An insufficient regulation}

\author{
Karen Andersen Cirera² [i] y Cristóbal Balbontín Gallo ${ }^{3}$
}

\begin{abstract}
RESUMEN
Los bordes costeros tienen vocación de puerto y de espacio público, además de poseer un valor ambiental y paisajístico. Sin embargo, hoy en día la actividad portuaria del borde costero chileno y la presión inmobiliaria monopolizan el uso del suelo y se vinculan mal con la planificación territorial, generando situaciones que van en desmedro de la calidad de vida. A través de un análisis jurídico, se discutirán las razones de lo anterior, estableciendo una crítica en relación a la participación ciudadana y al valor del paisaje y medioambiente en la planificación del territorio costero.
\end{abstract}

Palabras claves: Borde costero, Espacio público, Planificación territorial, Sistema portuario chileno.

\begin{abstract}
The coastal edges have a vocation for port and public space, as well as having an environmental and landscape value. However, nowadays the port activity of the Chilean coastal border and the real estate pressure, monopolizes land use in a way that is badly linked to territorial planning, generating situations that are detrimental to the quality of life and sustainability. Through a legal analysis, the reasons for the above will be discussed, establishing a critique in relation to citizen participation and the value of the landscape and environment in the planning of the coastal territory.
\end{abstract}

Keywords: Coastal edge, Public space, Territorial planning, Chilean port system. 
El borde costero comprende la conjunción relativamente difusa de aquella franja del territorio nacional que comprende los terrenos adyacentes a bahías, golfos, estrechos, canales interiores que, junto al mar y la extensión de tierra que las olas bañan y desocupan alternativamente, conforman una unidad física y geográfica.

Siendo el agua el recurso y servicio ecosistémico base de los asentamientos humanos, sus bordes presentan una fuerte demanda de ocupación. En el caso de Chile, el recurso como los territorios de acceso a este, presentan las últimas décadas una creciente demanda de parte de las industrias de exportación, especialmente la agricultura y minería. Sin embargo, la relación de las comunidades con los bordes de agua implica mucho más que el solo aprovechamiento del recurso. En Chile, los habitantes originarios vivieron y recorrieron las costas marítimas y fluviales, en búsqueda de alimentos. Los modos de habitar asociados a las actividades productivas artesanales de los bordes costeros, como la pesca, la extracción de algas y moluscos, fueron creando cultura con diversidad de matices a lo largo de todo el país. A su vez, dado el aislamiento geográfico del territorio chileno, estas costas cumplieron la función de acceso y salida de personas. Si bien hoy el sistema portuario está dominado por el factor tecnológico y de maquinaria, en sus orígenes la actividad portuaria requería grandes cantidades de mano de obra, lo que fue generando barrios y ciudades en torno a ella. Por otro lado, el disfrute estético del paisaje natural del océano Pacífico y su geografía costera, junto a los nuevos usos que trajo el siglo XX con la llegada del turismo, dan un nuevo atractivo a las costas del país y un nuevo valor económico a estos territorios que se comienzan a explotar como balnearios.

Todo lo anterior ha hecho que estos territorios del litoral sean altamente presionados por la actividad humana. Los paisajes de los bordes de agua se ven transformados por proyectos inmobiliarios que destruyen zonas de alta biodiversidad como humedales y dunas para maximizar las vistas de los desarrollos inmobiliarios. (Figura N01). Así los paisajes se transforman según las aspiraciones de los compradores, lo que lleva a que los proyectos inmobiliarios cerquen los accesos a las playas e incluso recreen ecosistemas ajenos a través de la construcción de lagunas artificiales de aguas cristalinas y vegetación exótica (Hidalgo et al. 2016a; 2016b).

Otra de las grandes presiones que sufre el paisaje costero chileno, es la ejercida por la infraestructura portuaria (Figura No2). La costa chilena se caracteriza por ser abierta y desabrigada, con pocos espacios geográficamente idóneos para el emplazamiento de puertos. Lo anterior implica que los espacios de acopio y almacenaje al interior de los puertos es restringido, generando una presión por expandirse territorialmente. En consecuencia, los puertos han tenido que intervenir el paisaje de localidades a través de grandes inversiones en rellenos y obras de abrigo, con el objeto de disponer de aguas tranquilas que faciliten la trasferencia de la carga. Según la cartera de proyectos del Ministerio de Obras Públicas, las inversiones en frentes de atraque proyectadas entre el año 2010 y 2020, consideraban 42 proyectos de ampliación de puertos y construcción de nuevos terminales portuarios ${ }^{4}$. Las grandes superficies de acopio, de carga y descarga y la escala de los containers y materiales ahí almacenados, transforman físicamente los paisajes y desplazan o eliminan usos tradicionales asociados a estas costas. Las zonas de seguridad propias de la acti-

Disponible en Chile 2020. Infraestructura portuaria y costera. Gobierno de Chile. Ministerio de Obras Públicas, 2009. http://www.dirplan.cl/ centrodedocumentacion/Documents/Politicas/Pol_Infra_Portuaria_Costera_2020.pdf (Fecha de consulta: 1 de febrero 2021) 
Figura $\mathrm{N}^{\circ} 1$.

Transformación del paisaje costero entre Reñaca y Concón entre 2004 y 2020

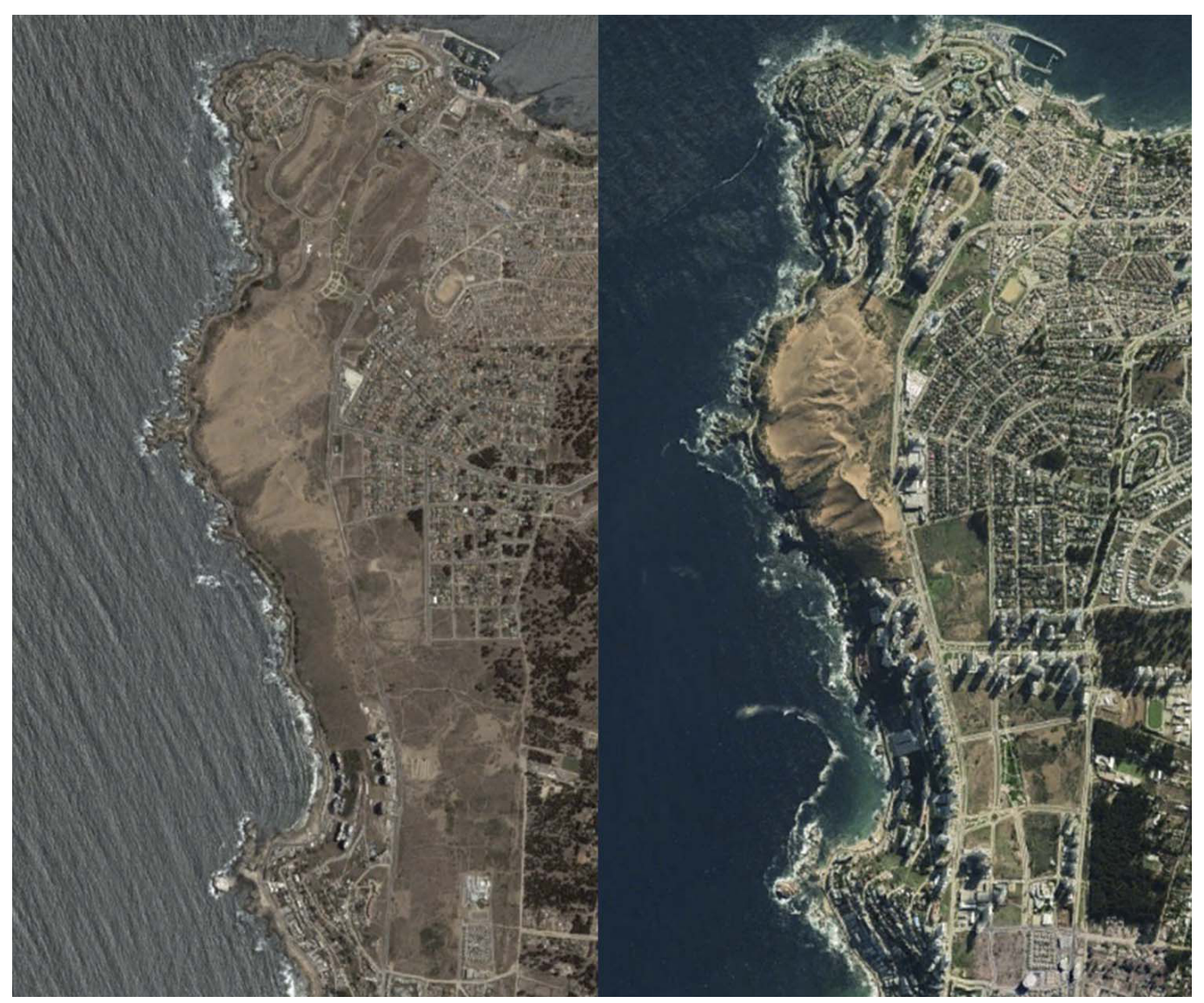

Fuente: Elaboración propia a partir de imágenes satelitales de los años 2004 y 2020, obtenidas de Google Earth.

vidad, trae como consecuencia paisajes cercados que separan al ciudadano de la experiencia del borde costero, generando un distanciamiento considerable entre los habitantes y el mar.

Diversos estudios sugieren que los espacios naturales, especialmente los bordes de agua se han ido produciendo socialmente las últimas décadas al servicio de la acumulación de capital, transformando espacios de contacto directo con la naturaleza en espacios de naturaleza producida socialmente, como lo observan Hidalgo et al. (2018) en su estudio sobre la presión inmobiliaria de proyectos de vivienda social sobre los humedales y cerros en las ciudades Valdivia y Valparaíso.

En este contexto, el presente artículo propone abordar el borde costero como un paisaje y un espacio público, el cual enfrenta conflictos socio-territoriales que se amparan de una normativa deficiente. Una revisión a los conceptos de paisaje, espacio público y conflicto socio-territorial darán el marco teórico a la problemática. 
Figura $\mathrm{N}^{\circ} 2$.

Localidades en que se emplazan puertos que transfieren carga de comercio exterior.

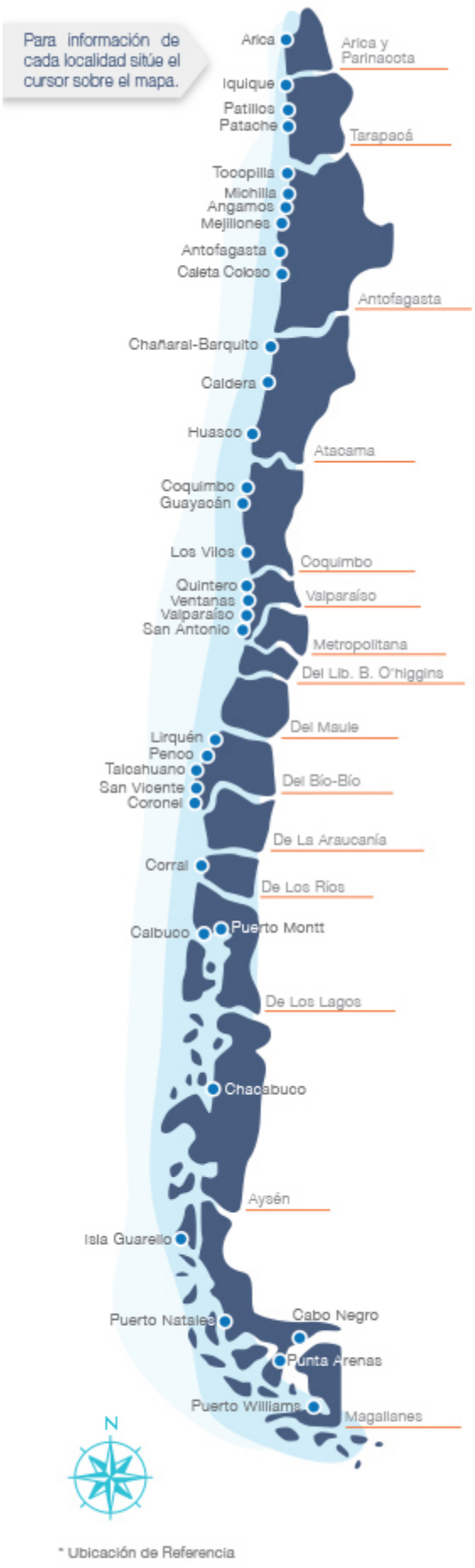

Fuente: Cámara portuaria y marítima de Chile https://www.camport.cl/mapa-portuario_new/home.html (Fecha de consulta: 1 de febrero 2021) 


\section{Paisaje, espacio público y conflicto socio-territorial}

El concepto de paisaje corresponde al sistema de relaciones entre componentes sociales, naturales, tangibles e intangibles que constituyen la identidad de los lugares con bordes de agua. El Convenio Europeo del Paisaje (CEP) del Consejo de Europa, adoptado en Florencia el año 2000, constituye el acuerdo e instrumento más avanzado en materia de protección paisajística, el cual obliga a los Estados que lo suscriben realizar su desarrollo normativo e integrar el paisaje en los instrumentos de planificación territorial (Zoido Naranjo, 2001). El convenio, establece como definición de paisaje "cualquier parte del territorio tal como es percibida por las poblaciones, cuyo carácter resulta de la acción de factores naturales y/o humanos y de sus interrelaciones" (CEP, 2000: 2). Para Joan Nogué (2014) la identidad de un lugar es dependiente de su paisaje.

Cuando estos espacios de bordes de agua se ven abandonados de su uso público y se produce una pérdida de sentido de lugar (Nogué, 2014), corren el riesgo de transformarse en lugares con una significación negativa (Andersen et al., 2019). Entendiendo los bordes de agua en tanto paisajes, la protección, gestión y ordenamiento de estos territorios debieran abordar la calidad de los lugares como condición de bienestar individual y social para un desarrollo sostenible, apartándose de una concepción patrimonial del paisaje. Así, la visión del Código Civil chileno que define a estos como Bienes Nacionales de Uso Público, estaría valorando estos territorios solo como parte de un espacio físico.

Si el borde costero chileno pertenece a la nación toda, estos deberían ser comprendidos como espacios públicos. Definimos espacios públicos como aquellos lugares accesibles a el(los) público(s) "que permiten el libre movimiento de todos, en el doble respeto de la accesibilidad y de la gratuidad" (Paquot, 2009: 1). Son espacios físicos y localizados, que conformarían lo que Ostrom (2011) define como comunes. Ostrom, va a denominar la tragedia de los comunes, al hecho de que estos bienes de todos implican una dificultad mayor para ser gobernados. Ahora bien, a partir de la tesis planteada por Harvey (2013), sobre la acumulación de capital de los grandes poderes financieros producto de los procesos de crecimiento y extensión de las ciudades a partir del siglo $X I X$, vemos que igualmente los espacios públicos en las ciudades mantienen su importancia en tanto que espacio de producción social. Por otro lado, la segregación de las ciudades chilenas, ha traído espacios públicos segregados, con menos diversidad y sociabilidad, dado a la pérdida de su carácter heterogéneo y accesible (Segovia \& Oviedo, 2000). Sin embargo, es en los espacios públicos donde es posible el encuentro, que permite la comunicación, la generación de vínculos y la construcción de identidad (Andersen, 2015). Los espacios de bordes de agua además implican una experiencia sensible y sensorial compartida, y una estética apreciada por las personas que agudiza los sentidos (Kaplan \& Kaplan, 1989; Carr et al., 1992; Raymond et al., 2016). Una serie de estudios en el campo de la planificación y de la salud confirman la asociación entre contacto frecuente con áreas de diversidad ecológica y bienestar, reflejado en prevención y reducción de enfermedades, restauración psicológica, sensación de conexión con la naturaleza, fortalecimiento de la identidad personal y sentimiento de pertenencia con el lugar (Beery \& Wolf-Watz, 2014; Zhang et al., 2015; Southon et al., 2018).

Por otra parte, la concepción de espacio público al singular, no es geográfico ni localizado, sino definido como el fundamento de la comunidad política, lugar de legitimación de lo político y donde los actores políticos hacen visibles los problemas públicos. Esta definición de espacio pú- 
blico, síntesis de los trabajos de Habermas, Arendt y Sennet (Dacheux, 2008), es de interés para leer los conflictos socio-territoriales. Isaac Joseph (1995: 13) dirá que "la experiencia ordinaria de un espacio público nos obliga en efecto a no disociar espacio de circulación y espacio de comunicación" refiriéndose al espacio público físico y al político respectivamente.

Según la literatura, los conflictos socio-territoriales se multiplican en Latinoamérica a partir del auge del extractivismo y la economía basada en los recursos naturales. Estos a su vez, conllevan a transformaciones físicas y ambientales de los territorios y a conflictos sociales. Estos conflictos amenazan la "organización de un territorio identificado y apropiado en el sentido estricto o simbólico por un grupo social" (Stam \& Aliste, 2014: 70). Estos conflictos socio-territoriales conforman una acción colectiva, formada de múltiples acciones movilizadas en el territorio por causas específicas (Delamaza, 2019). Si bien se observa una relación entre conflicto socio-territorial y pobreza (Vega et al., 2019), estos no han sido menos importantes, influyendo directamente en modificaciones políticas. Estos conflictos muchas veces se inician por una confrontación de intereses a partir de un daño a un interés privado o particular o a partir de una defensa a una reserva natural por un grupo con motivaciones específicas (Delamaza, 2019), sin embargo, una diversidad de factores sociales, políticos y territoriales contribuyen a la aparición de un conflicto (Stamm \& Aliste, 2014).

La diversidad de actores e intereses que hacen uso y manejo del mar y de los ríos es amplia y en muchos casos, incompatibles. La importancia del acceso al mar para los grandes intereses económicos frente a la precariedad de las comunidades que viven de los recursos del mar es un ejemplo de las fuertes relaciones de poder que existen en estos territorios. La regulación de la gestión y aprovechamiento del recurso agua y sus accesos terrestres, puede consolidar estas estructuras de poder o bien ayudar a equilibrarlas. Un ejemplo de esto, son los procesos de apropiación y cercamiento de los litorales chilenos, con el consecuente desplazamiento de los pescadores artesanales (Camus \& Hidalgo, 2017).

No obstante lo anterior, las múltiples actividades humanas que en esta zona se desarrollan, generan conflictos de uso que no tienen relación únicamente con una presión ejercida sobre un territorio altamente atractivo, sino que tienen relación también con una deficiente administración y planificación territorial del borde costero. Históricamente la ocupación del borde costero se ha resuelto normativamente en virtud de leyes sectoriales (Andrade et al. 2008). A su vez, la promoción de la actividad portuaria por parte del Estado, ha tendido a monopolizar el uso de los bordes costeros.

La difícil regulación y control del uso del borde costero radica en parte por la dispersión de las competencias de la autoridad portuaria, que hoy se comparte entre muchos servicios públicos y ministerios que están relacionados a la infraestructura y movimiento de carga portuaria en Chile. En este sentido, la dictación del Decreto Supremo (D.S.) N 475, de 1994, del Ministerio de Defensa, que aprueba una Política Nacional de Uso del Borde Costero (PNUBC), constituye un avance. Sin embargo, subsisten dificultades entre esta normativa y el Decreto con Fuerza de Ley (D.F.L.) de 1960, sobre concesiones marítimas; el decreto supremo de 2018, de Defensa, que sustituye el reglamento sobre concesiones marítimas fijado también por decreto supremo del año 2005 de la misma cartera; la Ley No 20.249 o Ley Lafkenche, destinada a proteger los asentamientos indígenas en el borde costero, así como con los instrumentos de planificación territorial de suelo urbano 
que norman igualmente el borde costero. Nuestro propósito es advertir en este artículo algunos de estos problemas que -no obstante, los avances- siguen amenazando una planificación armónica del borde costero. Los conflictos socioterritoriales presentados en este artículo son ejemplos de cómo el marco normativo no es capaz de resolver estos conflictos, sino que más bien los agrava.

\section{Aspectos metodológicos}

Para el diagnóstico de la situación, la investigación realizará un análisis jurídico-dogmático de la normativa, doctrina y jurisprudencia nacional. Es decir, se revisará de forma exhaustiva la regulación general y la normativa específica con el fin de identificar las formas de planificación territorial del borde costero y su relación con los demás instrumentos de planificación.

A nivel propositivo, el método de investigación combina una aproximación teórica desde las ciencias sociales, que servirá de clave de lectura teórica de los conflictos socio-espaciales. La metodología comprende un estudio de fuentes académicas y de prensa escrita sobre conflictos socio-territorial ubicados en bordes costeros. Se estudiaron aquellos casos en los cuales la normativa existente ha sido un facilitador del conflicto. Del mismo modo, se intentará identificar los elementos argumentativos que puedan servir para ofrecer una solución normativa a los problemas detectados.

El artículo se estructura en cuatro partes, primero da cuenta de la naturaleza jurídica del borde costero y de la planificación territorial del mismo a través de una lectura de los distintos cuerpos jurídicos que regulan este territorio, segundo pone en evidencia seis problemas del sistema de planificación territorial del borde costero y tercero da cuenta como estas deficiencias de la normativa se traducen en conflicto socio-territoriales que, por un lado, transforman los paisajes y, por otro, ponen en crisis el concepto de espacio público.

\section{Naturaleza jurídica del borde costero}

El Código Civil define la playa de mar como la "extensión de tierra que las olas bañan y desocupan alternativamente hasta donde llegan las más altas mareas" (Código Civil de Chile, 2020, artículo 594). En lo que importa, se considera -grosso modo- al borde costero como bien nacional de uso público, al identificarlo como aquel "cuyo dominio pertenece a la nación toda, como el de calles, plazas, puentes y caminos, el mar adyacente y sus playas" (Código Civil de Chile, 2020, artículo 595).

Ahora bien, la referencia a los bienes de dominio público la encontramos en la Constitución, en donde se señala: "La libertad para adquirir el dominio de toda clase de bienes, excepto aqueIlos que la naturaleza ha hecho comunes a todos los hombres o que deban pertenecer a la Nación toda y la ley lo declare así" (Constitución Política de la República de Chile de 1980, 2021, artículo $19 \mathrm{~N}^{\circ} 23$ ). Este precepto nos permite advertir que la nota distintiva de los bienes de dominio público es su destinación al interés público (Montt, 2011), constituyendo una excepción a la libertad para adquirir el dominio privado sobre toda clase de bienes. 
Además, el D.L N01939 precisa que son bienes de dominio público "los terrenos de playas fiscales dentro de una faja de 80 metros de ancho medidos desde la línea de más alta marea de la costa del litoral" (Decreto Ley N 1939, 1977, artículo 6º), los que no serán susceptible de enajenación a ningún título. Reafirma lo anterior el D.F.L. N ${ }^{\circ} 340$ del Ministerio de Defensa Nacional, que señala que es facultad privativa de dicha cartera de Estado "conceder el uso particular en cualquier forma, de las playas y terrenos de playas fiscales dentro de una faja de 80 metros de ancho medidos desde la línea de más alta manera de la costa litoral" (Decreto con Fuerza de Ley №340, 1960 , artículo $2^{\circ}$ ). Es decir, son necesariamente bienes de dominio público las playas entendidas como extensión de tierra que las olas bañan y desocupan alternativamente hasta donde llegan las más altas mareas, no así la tierra adyacente a las playas de una faja de 80 metros de ancho medidos desde la línea de más alta manera de la costa litoral, la que puede ser privada.

De lo anterior se desprenden dos consecuencias:

1) Que el mar como el borde costero son bienes de dominio público respecto de los cuales el Estado ejerce su titularidad. En cambio, en el caso del área de influencia terrestre, no existe un dominio público necesariamente de dichos bienes, sino que, normalmente, son públicos por afectación a utilidad pública en que bienes de dominio privado pueden pasar a ser bienes nacionales de uso público a través de expropiación.

2) Los bienes de dominio público están sujeto a un régimen de Derecho Público, por lo que para efectos de determinar el destino que les puede dar el Estado se debe atender ante todo a la ley, en virtud del principio de legalidad que fluye sobre todo del artículo $7^{\circ}$ inciso primero de la Constitución Política de la República.

Ahora bien, normalmente la titularidad del Estado sobre los bienes nacionales de uso público se ejerce a través del Ministerio de Bienes Nacionales, ente al cual le corresponde velar porque los bienes nacionales de uso público se respeten y conserven para el fin al cual estaban destinados, de acuerdo al artículo 19 y 64 del D.L. № 1939. No obstante, según el bien nacional de uso público del que se trate, otros órganos del Estado tienen competencia en la administración según su naturaleza y fines. Tal es el caso del mar y el borde costero.

En efecto, el D.F.L. № 340 del Ministerio de Hacienda, establece que corresponde a la Subsecretaría para las Fuerzas Armadas, el control, fiscalización y supervigilancia de toda la costa y mar territorial de la República y de los ríos y lagos navegables por buques de más de 100 toneladas, y en particular la facultad para otorgar la concesión "de las playas y terrenos de playas fiscales dentro de una faja de 80 metros de ancho medidos desde la línea de más alta marea" (Decreto con Fuerza de Ley $\mathrm{N}^{\circ} 340,1960$, artículo $1^{\circ}$ ). Precisemos que la concesión es el derecho de uso y explotación que otorga el Estado a un particular sobre un bien de dominio público, para los usos que se indican en el acto administrativo que la otorga, teniendo siempre en vista que ese uso esté afecto a un fin de interés general. Como consecuencia de lo anterior, corresponde a los Municipios, dentro de su territorio comunal, constituir concesiones en bordes de ríos o lagos que sean navegables por buques de menos de 100 toneladas, de acuerdo con la competencia residual que otorga el artículo $5^{\circ}$ de la ley № 18.695, Ley Orgánica Constitucional de Municipalidades.

En síntesis, es el propio ordenamiento jurídico el que autoriza la posibilidad de constituir permisos de uso o concesiones sobre el borde costero, fluvial o lacustre, lo que explica que el uso público y el libre acceso de la ciudadanía al borde costero pueda verse conculcado. 


\section{Planificación territorial del borde costero}

Como dijimos, la PNUBC, abre para Chile una nueva etapa en la planificación territorial de los espacios costeros. Respecto del mar y el borde costero dicha planificación tiene que ver con la zonificación para instalaciones portuarias e industriales, canales de circulación, instalaciones para pesca artesanal o industrial, acuicultura, zonas de fondeo, de protección ambiental, etc. que dice relación con la gestión del destino que se le puede dar al borde costero, señalando las actividades permitidas y prohibidas.

De acuerdo a lo anterior, esta política busca ante todo advertir la importancia y trascendencia de una ocupación equilibrada y armónica del borde costero que, al mismo tiempo, procura conciliar los diversos intereses regionales y locales. En dichas circunstancias, la PNUBC busca hacer compatible el desarrollo económico, el interés social, el uso racional de los recursos naturales, la protección del medio ambiente, la preservación de la cultura asociada a la pesca artesanal, entre otros intereses.

Con este propósito el artículo $2^{\circ}$ del D.S. $N^{\circ} 475$, de 1994, del Ministerio de Defensa, crea la Comisión Nacional del Uso del Borde Costero, cuya función principal es proponer al Presidente de la República acciones que impulsen la PNUBC (Cordero, 2011: 236). En dichas circunstancias, la Comisión Nacional puede proponer una zonificación del borde costero, formular proposiciones, sugerencias y opiniones a las autoridades encargadas de estudiar y aprobar los diversos planes comunales e intercomunales a fin de que exista coherencia en el uso del borde costero del litoral. Concretamente las zonificaciones se caracterizan y sancionan a través de un decreto supremo del Presidente de la República con firma del Ministerio de Defensa Nacional, en que declara un área costera reservada para uso preferente.

Esta declaración de área costera reservada tiene entonces por finalidad programática focalizar la acción de los organismos del Estado, mediante una coordinación forzada de los órganos del Estado que en ciertos casos busca estimular la inversión. Lo anterior siempre con el objetivo de lograr un desarrollo armónico del territorio y optimizar el uso de los bienes nacionales de uso público que conforman el borde costero, como materialización del imperativo constitucional establecido en el artículo $115^{\circ}$ de la Carta Fundamental (Cordero, 2011: 219).

Por su parte, a través del Decreto Exento No 35 de 1996, del Ministerio de Defensa Nacional, se aprueba el reglamento de la PNUBC que, entre otras cosas, contempla un proceso de participación ciudadana de los sectores de la sociedad que se relacionan con el borde costero, de tal manera que la zonificación refleje altos niveles de consenso (Cordero 2011: 223). De este modo, junto a los órganos del Estado que forman parte de la Comisión Regional de Uso del Borde Costero, participan del proceso de zonificación instituciones y organismos de la sociedad civil, universidades, organizaciones gremiales, sindicatos de pescadores, entre otros grupos de interés. Además, de un punto de vista ambiental, esta planificación se debe someter a Evaluación Ambiental Estratégica en virtud del artículo $7^{\circ}$ bis, que incorpora la ley $N^{\circ} 20.417$ a la ley $N^{\circ} 19.300$ sobre Bases Generales del Medio Ambiente (Cordero, 2011: 237).

De este modo la Zonificación del Borde Costero consta de una etapa de diagnóstico, una etapa de participación y una etapa de validación que es la confección de la memoria explicativa de- 
finitiva, la cartografía con escala revisión y aprobación por parte de la Comisión Regional de Uso del Borde Costero y finalmente la aprobación de la propuesta por la Comisión Nacional de Uso del Borde Costero, quien lo presenta al Presidente de la República para que, a través del Ministerio de Defensa, dicte el decreto supremo que declara las zonas de uso preferente del borde costero.

\section{Problemas subsistentes en el actual sistema de planificación territorial del borde costero}

La primera objeción que se advierte en la Zonificación del Borde Costero se refiere a la constitucionalidad de dicha planificación territorial. Concretamente el problema radica en que esta zonificación se materializa por decreto supremo, con lo cual ella puede adolecer de un vicio de inconstitucionalidad al implicar una limitación por vía de acto administrativo de ciertos derechos constitucionales. En efecto, la zonificación fija prohibiciones de ciertos usos de suelo al establecer usos preferentes, en otros casos posibilita usos alternativos a las zonas preferenciales definidas y en ciertos casos ella pretende definir prohibiciones y causales de caducidad a concesiones, por ejemplo, en el caso de las concesiones acuícolas. Incluso las zonas preferenciales de preservación ambiental -que puede imponer la Zonificación del Borde Costero- supone restricciones a proyectos portuarios o actividades económicas en la medida que no deben generar impactos negativos sobre el ecosistema natural, lo que se debe garantizar a través de la presentación de un Estudio de Impacto Ambiental. En particular, la Constitución garantiza a todas las personas: "El derecho a desarrollar cualquier actividad económica que no sea contraria a la moral, al orden público o a la seguridad nacional, respetando las normas legales que la regulen" (Constitución Política de la República de Chile de 1980, 2020, artículo 19 №21). A su vez, garantiza a todas las personas el derecho de propiedad sobre todas clases de bienes corporales incorporales, señalando que "sólo la ley puede establecer [...] las limitaciones y obligaciones que deriven de su función social" (Constitución Política de la República de Chile de 1980, 2020, artículo 19 N²4). Incluso señala que la "ley podrá establecer restricciones específicas al ejercicio de determinados derechos o libertades para proteger el medio ambiente" (Constitución Política de la República de Chile de 1980, 2020, artículo 19 N8). Esta reserva legal para limitar los derechos constitucionales precitados está fundada sobre todo en un principio de seguridad jurídica, como expresión de un Estado de Derecho.

Lo anterior ha sido objeto de una discusión importante en materia urbanística a propósito de los Instrumentos de Planificación Territorial contemplados en la normativa urbanística compuesta por Ley General de Urbanismo y Construcciones (LGUC) y la Ordenanza General de Urbanismo y Construcciones (OGUC), a doble título: por una parte, en materia urbanística las limitaciones y obligaciones del derecho de propiedad se imponen mediante los planes reguladores -comunal e intercomunal- que sancionados por actos administrativos (Decreto Alcaldicio y Resolución del Gobierno Regional respectivamente) imponen limitaciones al derecho de propiedad. Si bien la función social busca conciliar el ejercicio del derecho de propiedad con el bien común y las necesidades de la comunidad de racionalizar el uso del territorio, dichas restricciones deben realizarse -en principio- por ley (Rios, 1987: 57).

Ahora bien, a diferencia de la Zonificación del Borde Costero, el artículo 29 inciso segundo de la LGUC establece que los instrumentos de planificación urbana -sancionados por la autoridad competente- tendrán fuerza legal en su aplicación. Sin embargo, en la enumeración de los instru- 
mentos de planificación territorial que hace el artículo 29 de la LGUC no figura la Zonificación de Uso del Borde Costero.

En lo que importa, al revisar la legislación podemos advertir que la ley $\mathrm{N}^{\circ} 20.417$, que crea la Superintendencia del Medio Ambiente, agrega el artículo $7^{\circ}$ bis a la ley $N^{\circ} 19.300$, incorporando la Zonificación del Borde Costero entre los instrumentos de ordenamiento territorial que ella enumera ${ }^{5}$. Asimismo, el D.S. N430, de 1991, que fija el texto refundido, coordinado y sistematizado de la ley Nº19.892, de 1989 y sus modificaciones, Ley General de Pesca y Acuicultura, define la Zonificación de Borde Costero en su artículo $2^{\circ} N^{\circ} 57$ y lo identifica como

proceso de ordenamiento y planificación de los espacios que conforman el borde costero del litoral, que tiene por objeto definir los territorios y establecer sus múltiples usos, expresados en usos preferentes, los que no serán excluyentes, salvo en los casos que se establezcan incompatibilidades de uso con actividades determinadas en sectores delimitados en la misma zonificación y graficados en planos que identifiquen, entre otros aspectos, los límites de extensión, zonificación general y las condiciones y restricciones para su administración, en conformidad con lo dispuesto en la Política Nacional de Uso de Borde Costero, establecida en el Decreto Supremo № 475, de 1994, del Ministerio de Defensa Nacional.

Del mismo modo, lo hace el artículo 67 al mencionar la Zonificación de Borde Costero para efectos de fijación y modificación de las áreas adecuadas para el establecimiento de concesiones acuícolas. Por su parte, la ley $N^{\circ} 20.249$, que crea el Espacio Costero Marino de los pueblos originarios, establece que:

Serán susceptibles de ser declarados como espacio costero marino de pueblos originarios los bienes comprendidos en el borde costero que se encuentran bajo la supervigilancia y administración del Ministerio de Defensa Nacional, Subsecretaría de Marina, de conformidad con el artículo $1^{\circ}$ del Decreto con Fuerza de Ley No 340, de 1960, del Ministerio de Hacienda, sobre Concesiones Marítimas, o la normativa que lo reemplace (Ley $N^{\circ} 20.249$, 2008, artículo $\left.2^{\circ}\right)$.

Sin identificar expresamente la Zonificación del Borde Costero, la ley alude implícitamente a dicho mecanismo al identificar el D.S. N 475, de 1994, del Ministerio de Defensa Nacional para efectos de declarar el espacio marino de pueblos originarios. Finalmente, cabe mencionar la OGUC, que identifica la Zonificación del Borde Costero como una expresión propia de un instrumento de planificación territorial al señalar:

\footnotetext{
"Artículo $7^{\circ}$ bis.- Se someterán a evaluación ambiental estratégica las políticas y planes de carácter normativo general, así como sus modificaciones sustanciales, que tengan impacto sobre el medio ambiente o la sustentabilidad, que el Presidente de la República, a proposición del Consejo de Ministros, señalado en el artículo 71, decida. En todo caso, siempre deberán someterse a evaluación ambiental estratégica los planes regionales de ordenamiento territorial, planes reguladores intercomunales, planes reguladores comunales y planes seccionales, planes regionales de desarrollo urbano y zonificaciones del borde costero, del territorio marítimo y el manejo integrado de cuencas o los instrumentos de ordenamiento territorial que los reemplacen o sistematicen. En esta situación el procedimiento y aprobación del instrumento estará a cargo del Ministerio de Vivienda y Urbanismo, el Gobierno Regional o el Municipio o cualquier otro organismo de la Administración del Estado, respectivo".
} 
Los instrumentos de planificación territorial deberán reconocer las áreas de protección de recursos de valor natural, así como definir o reconocer, según corresponda, áreas de protección de recursos de valor patrimonial cultural. Para estos efectos, se entenderán por "áreas de protección de recursos de valor natural» todas aquellas en que existan zonas o elementos naturales protegidos por el ordenamiento jurídico vigente, tales como: bordes costeros marítimos, lacustres o fluviales, parques nacionales, reservas nacionales y monumentos naturales. En los casos indicados en el inciso anterior, los instrumentos de planificación territorial podrán establecer las condiciones urbanísticas que deberán cumplir las edificaciones que se pretendan emplazar en dichas áreas. Estas condiciones deberán ser compatibles con la protección oficialmente establecida para dichas áreas (Ordenanza General de Urbanismo y Construcciones, 1992, 2021, artículo 2.1.18)

Sin embargo, a pesar de las menciones que realiza la ley con anterioridad subsisten ciertas dificultades. Si bien la Ley General de Pesca y Acuicultura explícitamente ha dispuesto el carácter vinculante de la zonificación al momento de otorgar una concesión de acuicultura, la ley en general en ningún momento eleva a rango legal expresamente la Zonificación del Borde Costero para efectos de incorporarla al bloque de legalidad. Si bien es cierto que la OGUC la considera junto a los demás instrumentos de planificación territorial que forman parte del bloque de legalidad, subsiste la dificultad de que la misma OGUC esta sancionada por acto administrativo. Además, es aún discutible la cuestión de fondo, a saber, la constitucionalidad de incorporar actos administrativos a un bloque de legalidad por remisión que hace el legislador en el artículo 29 de la Ley General de Urbanismo y Construcciones, en circunstancias que el principio de reserva legal es un reflejo del principio de supremacía constitucional propio de un Estado de Derecho, en que la Constitución fija ciertas materias de ley y ciertos quorum para su aprobación como mecanismo especial de protección de los derechos fundamentales frente a un posible ejercicio arbitrario del poder del Estado, lo que requiere el concurso del Congreso Nacional.

La segunda crítica dice relación con la falta de sistematización de la Zonificación del Borde Costero con los otros instrumentos de planificación territorial. Si bien la OGUC reconoce la existencia de la Zonificación del Borde Costero no señala la forma como se va a relacionar con los otros instrumentos. Concretamente el artículo 2.1.2 de la OGUC, que contempla la jerarquía de instrumentos de planificación y el criterio según el cual los unos se deben armonizar con otros, no menciona a la Zonificación del Borde Costero, con lo cual se advierte la inexistencia de una regla que permita la convivencia armónica con este instrumento de planificación del Borde Costero. Dicho de otro modo, no está claro cuál es el valor de la Zonificación del Borde Costero en relación con los otros instrumentos de planificación territorial

Un tercer problema resulta de la dispersión normativa en la planificación territorial del borde costero. Desde un punto de vista de su planificación la Zonificación del Borde Costero establecida en el D.S. $N^{\circ} 475$, de 1994, de Defensa se refiere -como señala su artículo $2^{\circ}$ - a terrenos de playa fiscales ubicados dentro de una franja de ochenta metros de ancho, medidos desde la línea de la más alta marea de la costa del litoral, la playa, las bahías, golfos, estrechos y canales interiores, y el mar territorial de la República. Es decir, al borde costero marítimo. De tal forma, que la costa estará sujeta además a una planificación diferente según si se trata de suelo rural o urbano. Los Planes Reguladores Intercomunales que comprenden el ámbito de aplicación de 2 o más comunas, refieren tanto al suelo urbano como rural. No obstante, la diferencia en el tipo de uso de suelo 
se hace relevante en relación al resto de los instrumentos de planificación. De esta forma, la planificación del borde costero en zonas urbanas será abordado además por los Planes Reguladores Comunales y otros instrumentos de planificación territorial que regulan parte del suelo urbano, como planos y planes seccionales y de límite urbano. En el caso de tratarse de suelo rural la planificación territorial también corresponde al Plan Regional de Ordenamiento Territorial (PROT) de acuerdo a la ley N021.074. De esta forma el Ministerio de Defensa Nacional que ejerce, a través de la Subsecretaría para las Fuerzas Armadas, el control, fiscalización y supervigilancia de toda la costa y mar territorial de la República y de los ríos y lagos navegables por buques de más de 100 toneladas, tendrá que atender a distintas normas territoriales. Como consecuencia de lo anterior, se produce además una gran dispersión de autoridades que deben intervenir para edificar, desde la Dirección de Obras Municipales si se trata sólo de suelo urbano a la Secretaría Regional del Ministerio de Agricultura si se pretende subdividir y urbanizar en suelo rural, previo informe de la Secretaría Regional del Ministerio de Vivienda y Urbanismo, por aplicación del artículo 55 de la LGUC, que piensa el suelo rural bajo el supuesto de que el uso típico es agrícola ${ }^{6}$. Como resultado se aplica un estatuto que es enteramente ajeno al uso del borde costero.

La cuarta dificultad se refiere a la diversa intensidad regulatoria y categorías de tipos de usos de suelo del borde costero. En efecto, respecto del litoral, el reglamento de la Política Nacional de Uso del Borde Costero ha contemplado la existencia de ciertos tipos de zonificaciones. Sin embargo, no basta con atender sólo a ellas. También es necesario determinar si se trata de un uso de suelo urbano o rural. Si la zona del litoral que es objeto de zonificación recae sobre una zona urbana, la OGUC contempla coeficientes de constructibilidad, densidades, trazados viales, tipos de áreas verdes, actividades permitidas, subdivisión predial mínima, etc. En cambio, si el suelo es rural, la OGUC es pobre y escueta al momento de normar y admitir tipos de usos posibles. Por ejemplo, la regulación del paisaje está enteramente ausente de la OGUC. Esto último es importante pues "condiciona cualquier autorización, permiso o concesión sobre dicho espacio a los usos indicados" (Cordero, 2011: 229).

Una quinta dificultad es la falta de integración vinculante de autoridades y de marcos normativos ${ }^{7}$. En este sentido, la Ley No21.074, que modifica el artículo 17 letra a) de la Ley de Administración y Gobierno Regional, constituye un avance ya que establece el carácter vinculante del PROT (Balbontín, 2019: 421). En este mismo sentido el D.S. № 9, de 2018, de Defensa, que establece el

\footnotetext{
El artículo $55^{\circ}$ "es plenamente aplicable a las zonas costeras ubicadas en suelo rural, de manera que el uso que se puede dar a dicho espacio e fundamentalmente agrícola, permitiéndose levantar construcciones con dicho fin, o en su caso, para vivienda del dueño sus trabajadores" (Cordero, 2011: 229)

No obstante, lo anterior, la jurisprudencia administrativa ha intentado avanzar en este proceso de integración: "Como puede apreciarse, de las disposiciones anotadas se infiere, en lo que interesa, que los Órganos de la Administración del Estado, en el otorgamiento de concesiones deben, necesariamente, actuar de manera responsable, coordinada y eficiente, con miras a satisfacer en forma unida y uniforme las necesidades públicas, lo que implica que el otorgamiento de concesiones debe llevarse a cabo en le medida que se condiga con los usos, prohibiciones y restricciones establecidas por la zonificación del uso del borde costero, por el plan nacional y regional de uso de borde costero y por los planes regionales de desarrollo urbano como de los planes reguladores intercomunales. Consecuente con lo expuesto, es dable concluir que es el propio ordenamiento jurídico el que ha conferido a esa Secretaría de Estado (Ministerio de Defensa) la atribución privativa de conceder el uso de las aguas marítimas, la cual ejerce a través de un procedimiento reglado, con requisitos y exigencias que debe cumplir los interesados en obtener dicho beneficio, velando que en su decisión no se afecten los derechos de los demás concesionarios y teniendo en consideración los mejores usos del sector concesionado conforme a la Política Nacional de Uso de Borde Costero del litoral de la República fijada mediante decreto supremo $N^{\circ}$ 475, de 1994, del Ministerio de Defensa Nacional." (Aplica dictamen №35.441, de 2015, de la Contraloría General de la República).
} 
reglamento del D.F.L. N³40, de 1960, sobre concesiones marítimas, constituye igualmente una mejora al estatuir su artículo 14 que

el ejercicio de la facultad discrecional de otorgar concesiones marítimas deberá ajustarse a los usos y criterios de compatibilidad establecidos en la Zonificación Regional del Borde Costero que se encuentre vigente, cuando esta haya sido publicada en el Diario Oficial, incluyendo la memoria de zonificación (Decreto Supremo $N^{\circ} 9$ del Ministerio de Defensa Nacional, 2018, artículo 14).

Con todo el problema de su falta de carácter legal y vinculante es especialmente sensible en relación con los organismos y normativas sectoriales. En efecto, en la zona costera hay actividades extractivas vinculadas a los recursos naturales (energía, minerales, hidrocarburos, gas, etc.) regulados por normas sectoriales que no están debidamente coordinadas con la planificación territorial y que pretenden primar sobre estas, lo que genera conflictos territoriales. Un ejemplo de tal colisión, es la ley $N^{\circ} 20.249$ de 2008, que crea el Espacio Costero Marino de los Pueblos Originarios, le confiere la administración de un espacio marino a asociaciones y comunidades que invocan el uso consuetudinario (artículo $6^{\circ}$ ). No obstante, la Ley de Pesca contempla la prioridad de su legislación sectorial sobre concesiones marítimas y áreas de manejo preestablecidas frente a otras destinaciones espaciales. Otro ejemplo de supremacía de la legislación sectorial en materia de infraestructura necesaria para la explotación de recursos naturales, la encontramos en la OGUC donde se hace una remisión a las normas sectoriales en materia energética, sanitaria y transportes, señalando -sorprendentemente- que en zona rural este tipo de infraestructura "estarán siempre admitidas" (Ordenanza General de Urbanismo y Construcciones, 1992, 2021, artículo 2.1.29) para lo cual se sujetaran a la regla general en materia de suelo rural del artículo 55 de la LGUC. Como se puede advertir, planificación territorial del borde costero, que tiene un fuerte acento en determinar el destino de diversos recursos naturales, cede lugar a la normativa sectorial producto de una falta de coordinación forzosa con la planificación territorial${ }^{8}$.

Una sexta y última objeción se refiere a la excesiva centralización que aún afecta a la Zonificación de Uso del Borde Costero. Si bien ella se lleva a cabo a propuesta de una Comisión Regional De Uso De Borde Costero, finalmente su sanción se efectúa por decreto supremo del Presidente de la República a través del Ministerio de Defensa, lo que contraviene toda la tendencia actual de descentralización de los instrumentos de planificación territorial.

\footnotetext{
En este sentido el PROT constituye un avance al estatuir la macro zonificación del territorio de la región, a fin de lograr un desarrollo sustentable, estableciendo condiciones para la localización de infraestructuras y actividades productivas junto con áreas para su localización preferente. El incumplimiento de estas condiciones "provocará la caducidad de las autorizaciones respectivas"; caducidad de las "autorizaciones" que -en sentido amplio- alcanzaría tanto a los planes de manejo forestal y al otorgamiento de concesiones como a las autorizaciones sectoriales para la explotación de un recurso natural. Además se establece que será de cumplimiento obligatorio para los "servicios públicos que operen en la región (...)" de acuerdo a lo preceptuado por el artículo 17 de la ley № 21.074 que modifica la ley Nº 19.175 sobre Gobierno y Administración Regional. Con todo, cabe indicar que esta pendiente la dicatción del reglamento de la ley N²21.074 como del Plan Nacional de Ordenamiento Territorial (PNOT) para lograr la plena puesta en marcha del PROT.
} 


\section{Conflictos socio-territoriales como efecto de la des- regulación territorial}

La lectura crítica de la normativa del borde costero nos da cuenta de una planificación deficiente que se traduce en conflictos socioterritoriales. Este apartado da cuenta de algunos de estos conflictos producto de los problemas subsistentes en el actual sistema de planificación territorial del borde costero.

Un caso es la ciudad de Valparaíso, donde el proyecto del proyecto "Mall Puerto Barón", adjudicado por el mismo grupo comercial del Mall de Antofagasta, para remodelar el borde costero de Valparaíso generó un importante movimiento de protesta. En la especie, el Plan Maestro vigente de la empresa Portuaria de Valparaíso define una zona que media entre el sector de Barón y calle Edwards. Esta zona se destina a desarrollo urbano, usos culturales, turísticos, recreativos o servicios. Esta concesión se adjudicó el año 2006, y posteriormente mediante un acto administrativo la figura se amplió a la posibilidad de compraventa, agudizando, por lo tanto, el quiebre con la ciudadanía frente a la susceptibilidad de destinos que se le podía dar al borde costero. La ciudadanía en Valparaíso y el municipio se mostraron críticos a este proyecto, abogando por el uso público de su litoral y la protección del patrimonio de la ciudad de Valparaíso. Finalmente, el proyecto fue abandonado como consecuencia de un pronunciamiento de la Corte Suprema que decidió, en diciembre de 2017, acoger el reclamo de ilegalidad interpuesto por un grupo de ciudadanos en contra de la llustre Municipalidad de Valparaíso, dejando sin efecto el permiso concedido en 2013 por ésta para la edificación del proyecto inmobiliario en cuestión.

Otro caso conflictivo en relación al borde costero es el caso de la construcción el año 2011 de un hotel por la Inmobiliaria Punta Piqueros S.A., en el límite de Viña del Mar y Concón, próximos a los Santuarios de la Naturaleza Roca Oceánica y Dunas de Concón. Este permiso de edificación fue otorgado por el Municipio a través de un decreto alcaldicio amparándose en la ley No 13.364 de 1959, también conocida como Ley Lorca, que permite a la Municipalidad de Viña del Mar autorizar ciertos proyectos inmobiliarios en el borde costero. La oposición de la ciudadanía se basó en varios fundamentos: el riesgo que representa el emplazamiento del hotel en la cota de oleaje del mar, la destrucción del ecosistema y la defensa al uso público del borde costero. Si bien las obras del Hotel Piqueros se paralizaron el año 2013 a través de una acción legal presentada por el Comité por la Defensa del Patrimonio Histórico y Cultural de Viña del Mar, el siguiente año se aprobó el Estudio de Impacto Ambiental y se reactivó la obra. El año 2016, el Segundo Tribunal Ambiental de Santiago resolvió suspender el decreto alcaldicio que dio el permiso de edificación al Hotel Punta Piqueros y suspender las obras (Fig.2). Finalmente, con fecha 6 de noviembre de 2017, la Corte Suprema resuelve el Recurso de Casación Rol N97.792-2016, confirmando la sentencia del Segundo Tribunal Ambiental, Rol N86/2015, que invalidó la RCA del proyecto Hotel Punta Piqueros, ordenando retrotraer su procedimiento de aprobación ante el SEIA, reconociendo el deber legal de establecer una línea base que describa las circunstancias del medio ambiente en forma previa a la ejecución del proyecto (Araya, 2019).

Sin perjuicio de lo anterior, el problema de fondo es el hecho mismo que sea posible llevar a cabo un desarrollo inmobiliario turístico en el borde costero de Viña del Mar contraviniendo su condición fundamental de bien nacional de uso público definido por el D.L. No 1939 de 1977, el Artículo 595 del Código Civil, entre otros cuerpos legales. Si bien, uno de los principales propósitos 
de la Ley Lorca era evitar que la construcción de edificios beneficiara solo a la actividad privada, con el consecuente menoscabo de la costa y su paisaje perjudicando el interés general (Araya, 2019), esta ley no es prohibitiva, en la medida que los desarrollos tengan un tenor turístico. En virtud de esta excepción que introduce la Ley Lorca del año 1959 en la $V$ región, junto a un Plan Regulador Comunal y un Plan Regulador Intercomunal que autorizan el uso de hotel en su zonificación, es que este permiso de edificación fue entregado.

Figura $\mathrm{N}^{\circ} 3$.

Protesta de vecinos de Concón

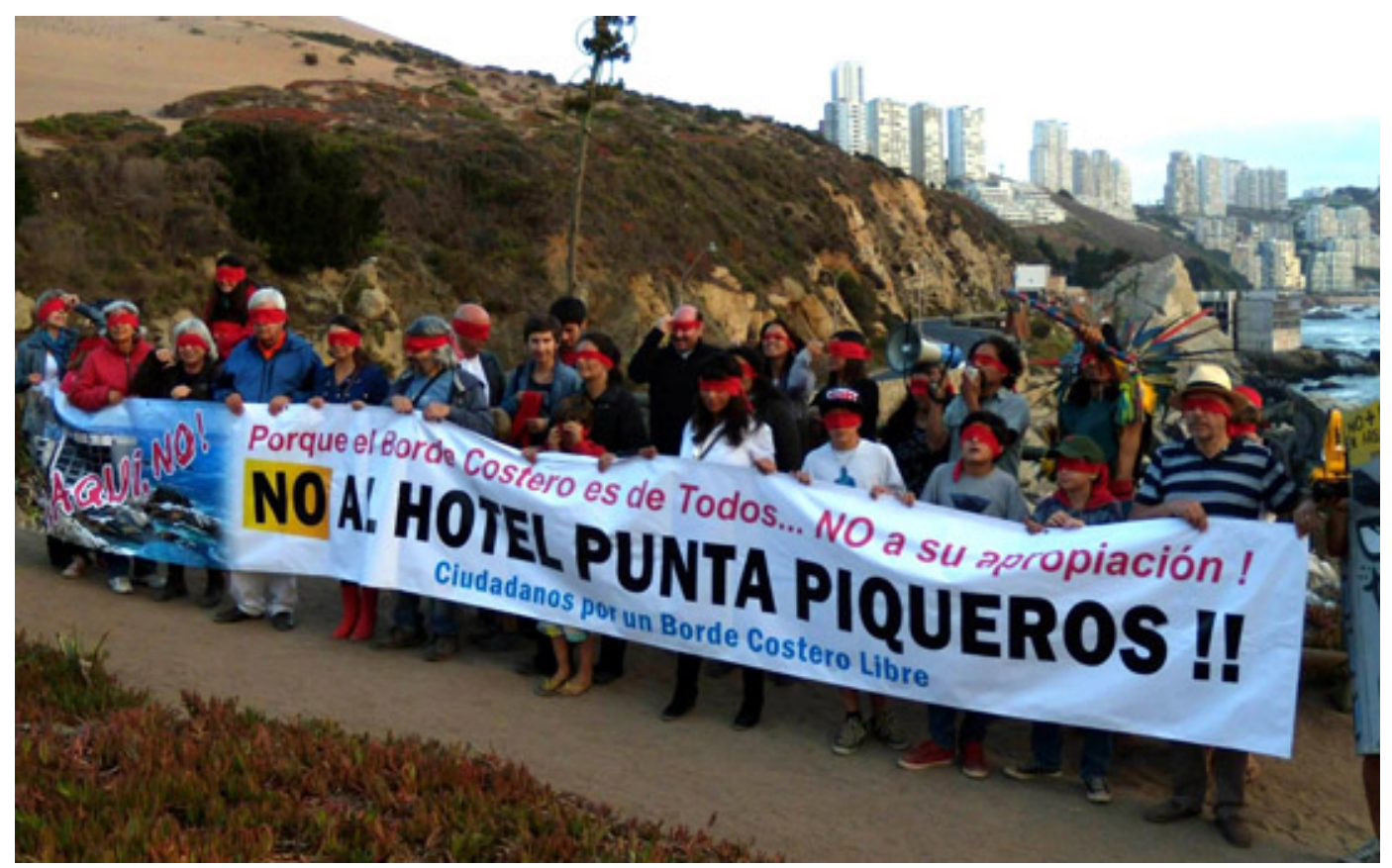

Fuente: Ciper. 01.07.2016 https://ciperchile.cl/2016/07/01/vecinos-de-concon-acusan-que-hotel-punta-piqueros-se-construye-al-margen-de-la-legalidad/ (Fecha de consulta: 20 enero 2021)

Sin embargo, en el caso de la Empresa Portuaria de Antofagasta, la cual concesiona un "área de negocios de Infraestructura y Servicios para el Turismo y Comercio Regional"9 que se la adjudica Mall Plaza Antofagasta, desde el año 2006 hasta el año 2034, los acontecimientos han tenido otro alcance. Esta licitación considera un proyecto de 10 hectáreas con más de 160 mil metros cuadrados construidos. Los espacios públicos en el borde costero, creados por esta iniciativa, se estructuran en torno a los espacios comerciales del Mall. Antes de la construcción del proyecto, la zona se encontraba en un estado de deterioro y contaminación. Para llevar a cabo este proyecto se limitó la extensión del puerto, creando el Puerto de Mejillones y desviando carga hacia él. El Proyecto del Mall ha tenido una amplia aceptación ciudadana y fue galardonado con el Premio de Arquitectura Paisajística y Mejoramiento del Entorno Industrial, iniciativa que busca reconocer a aquellas empresas o industrias que desarrollan obras de recuperación de espacios deteriorados y 
entregados al uso de la comunidad. Lo anterior, no obstante, no es óbice al argumento de fondo: estos proyectos no corresponden al sentido o alcance de las concesiones sobre el borde costero.

\section{Conclusiones}

La llamada coloquialmente "privatización del borde costero", que amenaza este disfrute de las costas de ríos y mares, en tanto bienes comunes a todos los ciudadanos, es en parte el resultado de la proliferación inorgánica de concesiones sobre el borde costero que atenta justamente en contra la racionalización del espacio de una forma que permita lograr un desarrollo armónico entre las distintas formas de uso público. Una evidencia de lo anterior es que, si bien una parte importante de estas concesiones a privados están asociadas a la actividad portuaria, otras concesiones han privilegiado la rentabilidad (Texido, 2008) a través de proyectos inmobiliarios, lo que constituye un contrasentido a la razón de ser de este tipo de actos jurídicos de derecho público. Dicho de otro modo, la construcción de este tipo desarrollos inmobiliarios corresponderían a usos excluyentes para espacios que corresponden en principio al "uso público".

En efecto, más allá de la discusión de la calidad de los espacios públicos que estas concesiones pueden entregar a la ciudad, la reflexión que nos interesa es determinar cuáles son los actores que operan en esta forma de construir ciudad y espacio público, y cuáles son sus intereses. Por un lado, la empresa portuaria está planificando los territorios de borde costero a través de los Planes Maestros que establecen la zonificación de estos espacios. Por otra parte, el municipio, que es el representante de la ciudadanía en el proceso de planificación, queda relegado a un segundo plano ya que las decisiones se toman sectorialmente a nivel central. ¿Cuál es el diálogo que existe entre la empresa portuaria y su respectivo Plan Maestro y aquellos objetivos establecidos por el Plan de Desarrollo Urbano, el Plan Regulador Intercomunal y el Plan Regulador Comunal de la comuna costera? Podemos constatar que esta coherencia de objetivos entre los instrumentos de planificación territorial definidos por la Ley General de Urbanismo y los instrumentos del sistema portuario nacional no está garantizada. Si bien en el caso de Antofagasta, el Plan Maestro de la Empresa Portuaria es reflejo del Plan Regulador Comunal de Antofagasta, contrariamente en Valparaíso, las visiones de desarrollo de estos dos instrumentos no son consistentes.

No obstante, es necesario valorizar la participación de los distintos actores -públicos y privados- en lo que se refiere a la existencia a una deliberación y coordinación compartida de iniciativas. Hoy existen los comités portuarios de servicios públicos, establecido en el D.S. No 105 del Ministerio de Transporte y Telecomunicaciones, que son figuras que están en línea con experiencias internacionales como el gobierno corporativo de la autoridad portuaria de Hamburgo, que inserta dentro de la orgánica de una Autoridad Portuaria un Consejo de Vigilancia donde no sólo están representados los intereses de la Autoridad Portuaria sino también la de otros servicios públicos y la de operadores privados de los puertos. En esta materia tiene especial relevancia analizar el fortalecimiento de los Consejos de Coordinación Ciudad Puerto que considera la Ley de Modernización del Sector Portuario, la cual dispone que le corresponde al Ministerio de Transportes y Telecomunicaciones:

Procurar un desarrollo armónico entre los puertos y la ciudad, cuidando en especial el entorno urbano, las vías de acceso y el medio ambiente. Para estos efectos, se creará una 
instancia de coordinación a nivel de región, denominada Consejo de Coordinación Ciudad-Puerto, en la que tendrán participación, a lo menos, un representante del Gobierno Regional y uno por cada municipalidad donde se encuentre el puerto (Ley $N^{\circ} 19.542,1997$, 2011, artículo 50, letra d).

Se constata como la planificación existente sobre el borde costero y otros bordes de agua, pone en riesgo su definición original de bien nacional de uso público. Se constata asimismo a través del análisis de algunas experiencias recientes de proyectos de construcción en el borde costero nacional como esta planificación crea fricciones y conflictos con la ciudadanía. A través de un análisis jurídico de este territorio se presentan uno a uno los problemas e incongruencias del actual sistema de planificación de estas áreas social, económica y ambientalmente sensibles. En síntesis, se observa una falta de sistematización normativa de los diversos instrumentos de planificación del borde costero y, por otra parte, el riesgo de una planificación dispar e incongruente del borde costero, que producen a su vez una colisión entre los distintos órganos y autoridades que ejercen la supervigilancia, fiscalización y control de carácter territorial sobre el borde costero. Para ello es necesario avanzar hacia una genuina descentralización de la planificación territorial, en su carácter vinculante y en la integración adecuada de los estatutos orgánicos y normativos que tienen impacto sobre el territorio.

\section{Referencias}

ANDERSEN, K. La contribution des habitants et des usages à la production des espaces publics: le cas du tremblement de terre et tsunami au chili, février 2010 (Doctorado) Francia: Université Paris-Est, 2015.

ANDERSEN, K., LEHNER, D., ZUMELZU, L, A., \& MÉNDEZ, P. Una metodología para evaluar los usos públicos y la percepción de los bordes fluviales: Valdivia como caso de estudio. Urbano, 2019, Vol. 22, N40, p. $28-45$.

ANDRADE, B., ARENAS, F. \& GUIJÓN, R., Revisión Crítica del marco institucional y legal chileno de ordenamiento territorial costero. Revista de Geografía Norte Grande, 2008, №41, p.23-48.

ARAYA, A. Análisis del caso proyecto Hotel Punta Piqueros a la luz del desarrollo sustentable y los efectos del cambio climático. (Licenciatura en Ciencias Jurídicas y Sociales). Universidad de Chile, 2019.

BALBONTÍN, C. Los instrumentos de planificación territorial como mecanismo adecuado para proteger el derecho humano de los indígenas al territorio, Revista lus et Praxis, 2019, Vol. 25, №3, p. 409-424.

BEERY, T.H. \& WOLF-WATZ D. Nature to place: rethinking the environmental connectedness perspective, Journal of Environmental Psychology, 2014, Vol. 40, p.198-205.

BUDDS, J., La demanda, evaluación y asignación del agua en el contexto de escasez: un análisis del ciclo hidrosocial del valle del río La Ligua, Chile. Revista de Geografía Norte Grande, 2012, N52, p.167-184. 
CAMUS, P. \& HIDALGO, R. "Y serán desplayados". Recorrido histórico sobre los bienes comunes, pescadores artesanales y control legal, Historia Crítica. No. 63, 2017, p. 97-116.

CARR, S., FRANCIS, M., RIVLIN, L.G. \& STONE, A. M. Public Space, Cambridge: Cambridge University Press, 1992.

CONSEJO DE EUROPA. Convenio Europeo de Paisaje. Florencia, 2000.(Consulta 10/04/2021) https://www.mapa.gob.es/es/desarrollo-rural/planes-y-estrategias/desarrollo-territorial/convenio. $\operatorname{aspx}$

CORDERO, E. Ordenamiento Territorial, justicia ambiental y zonas costeras. Revista de Derecho de la Pontificia Universidad Católica de Valparaíso, 2011, Vol. XXXVI, p. 209-249.

DACHEUX, E. (Coord). L'Espace public. Paris: CNRS Éditions, 2008.

DELAMAZA, G. Consecuencias políticas de los conflictos socio-territoriales. Hacia una conceptualización pertinente. Revista Austral de Ciencias Sociales, 2019, Vo. 37, p.139-160.

DELAMAZA, G., MAILLET, A., \& MARTíNEZ NEIRA, C. Socio-Territorial Conflicts in Chile: Configuration and Politicization (2005-2014). European Review of Latin American and Caribbean Studies, 2017, Vol. 104, p. 23-46.

DIRECCIÓN DE OBRAS PORTUARIAS. MOP Infraestructura Portuaria Costera, 2020. .(Consulta 10/04/2021) http://www.dop.cl/acercadeladireccion/Documents/Infraestructura\%2OPortuaria\%20y\%20Costera\%20Chile\%202020.pdf

GODINEZ, W. \& GARCÍA PEÑA, J. (coord.). Metodologías: Enseñanza e Investigación Jurídica. México: Ediciones Universidad Nacional de México, Instituto de Investigaciones Jurídicas, 2015.

HARVEY, D. Ciudades rebeldes. Del derecho a la ciudad a la revolución urbana. Editorial Akal, 2013.

HARVEY, D., EI "nuevo" imperialismo: acumulación por desposesión, Biblioteca CLACSO, 2014. (Consulta 10/11/2020) http://biblioteca.clacso.edu.ar/clacso/se/20130702120830/harvey.pdf

HIDALGO, R., CAMUS, P., ALVARADO, V., PAULSEN, A. \& OLEA, J. Aguas de ficción a la carta: la producción de naturaleza como nicho de renta. Bienes comunes y espacio urbano exclusivo en torno a las crystal lagoons. En Alvarado, C., Gómez, R., Hidalgo, R., (Ed) Expresión territorial de la fragmentación y segregación. México: Praxis Digital 9 - Universidad Autónoma del Estado de Morelos, 2016a, p. 13-30

HIDALGO, R., RODRÍGUEZ, L., PAULSEN, A., \& ALVARADO, V. La naturaleza como obstáculo: perspectivas críticas del avance de la vivienda social e infraestructura vial sobre los humedales en la ciudad de Valdivia, Chile. Investigaciones Geográficas, 2018, N56, 2018, p. 27-44.

HIDALGO, R., SANTANA, D., ALVARADO, V., ARENAS, F., SALAZAR, A., VALDEBENITO, C. \& ÁLVAREZ, L., En las costas del neoliberalismo. Naturaleza, urbanización y producción inmobiliaria: experien- 
cias en Chile y Argentina, Serie GEOlibros $N^{\circ} 23$, Instituto de Geografía, Pontificia Universidad Católica de Chile -Instituto de Geografía, Pontificia Universidad Católica de Valparaíso, 2016b.

JOSEPH, I. (dir) Prendre place. Espace public et culture dramatique, Paris: Editions Recherches/ Plan Urbain, 1995.

KAPLAN, R. \& KAPLAN, S. The experience of nature: A psychological perspective. Cambridge University Press, 1989.

MASJUÁN, F. INGENIERÍA E.I.R.L. (CIMA E.I.R.L.), Estudio "Diagnóstico del Modo de Transporte Marítimo". Realizado por la empresa por encargo de la Subsecretaría de Transportes, 2008. .(Consulta 15/10/2020) http://www.sectra.gob.cl/biblioteca/detalle1.asp?mfn=3079

MINISTERIO DE ECONOMÍA, FOMENTO Y TURISMO. GOBIERNO DE CHILE. Sistema de Empresas Públicas. Compilado estadístico de los Puertos del Estado, ,. 2017. .(Consulta 10/04/2021) http:// www.sepchile.cl/documentacion/estadisticas-portuarias/?no_cache=1

MONTT, S. El Dominio público. Estudio de su régimen especial de protección y utilización. Santiago: Cono Sur, 2001.

NOGUÉ, J., Sentido del lugar, paisaje y conflicto. Geopolítica(s). Revista de estudios sobre espacio y poder, 2014, Vol. 5, N², p. 155-163.

OECD/ITF, Ports Policy Review of Chile, 2016. (Consulta 10/04/2021)https://www.itf-oecd.org/sites/default/files/docs/ports-policy-review-chile.pdf

OSTROM, E. El gobienos de los bienes comunes. La evolución de las instituciones de acción colectiva. 2da. ed. México, UNAM-CRIM-FCE, 2011.

PAQUOT, T., L'Espace public, Paris: Editions La Decouverte, 2009

RAYMOND, C., GOTTWALD, S., KUOPPA, J. \& KYTTÄ, M. Integrating multiple elements of environmental justice into urban blue space planning using public participation geographic information systems. Landscape and Urban Planning, 2016, Vol. 153, p.198-208.

REPÚBLICA DE CHILE, Código Civil de Chile, Santiago de Chile: Editorial Jurídica de Chile, 2020

REPÚBLICA DE CHILE, Constitución Política de la República De Chile de 1980 (CPE). Santiago de Chile: Editorial Jurídica de Chile, 2020.

REPÚBLICA DE CHILE, Diario Oficial, [1874], 2021(Consulta 10/01/2021) https://www.diariooficial. interior.gob.cl/

REPÚBLICA DE CHILE, Ordenanza General de Urbanismo y Construcción (OGUC). Decreto N47 del Ministerio de Vivienda y Urbanismo, Santiago de Chile: Galas Ediciones [1992], 2021. 
RíOS, L. El principio Constitucional de la Función Social de la Propiedad. Revista de Derecho y Jurisprudencia, 1987, tomo $84, \mathrm{~N}^{\circ} 2$, p. 57-73.

ROJAS, M. \& BUSTOS, V. Valparaíso: el derecho al patrimonio. Revista Antropologías del Sur, 2015, No3, p. 155-173.

SEGOVIA, O. \& OVIEDO, E. Espacios públicos en la ciudad y el barrio. En Segovia, O.; Dascal, G. (editores). Espacio público, participación y ciudadanía. Santiago de Chile: Ediciones Sur, 2000.

SOUTHON G., JORGENSEN, A., DUNNETT, N., HOYLE, H. \& EVANS, K. Perceived species-richness in urban green spaces: Cues, accuracy and well-being impacts, Landscape and Urban Planning, 2018, Vol. 172, p.1-10

STAMM, C. \& ALISTE, E. El aporte de un enfoque territorial al estudio de los conflictos socio-ambientales. Revista Faro, 2014, Vol. 2 N²0, p. 66-78.

TEXIDO, A. Actualidad de los proceso de Reconversión Portuaria en Chile. Revista Portus, RETE, 2008, N¹5, p. 36-41.

VEGA, A., ACUÑA, A., VIVALLOS C., BLOOMFIELD, F. \& HOYUELA, J. Los nuevos conflictos socioterritoriales y el espacio geográfico en Chile, Tiempo y Espacio. 2020, Núm. 43: Geografía, p.79-85.

ZHANG, Y., VAN DIJK, T., TANG, J. \& VAN DEN BERG, A., Green space attachment and health: A comparative study in two urban neighbourhoods, International Journal of Environmental Research and Public Health, 2015, Vol. 11, p. 14342-14363

ZOIDO NARANJO, F. La Convención Europea del Paisaje y su aplicación en España. Ciudad Y Territorio Estudios Territoriales (CyTET), 2001, 33(128), 275-281. .(Consulta 10/04/2021) https://recyt. fecyt.es/index.php/CyTET/article/view/75029 
